\title{
Single step electrosynthesis of NiMnGa alloys
}

\author{
Berna Özkale ${ }^{\mathrm{a}, *}$, Fajer Mushtaq ${ }^{\mathrm{a}}$, Jordina Fornell ${ }^{\mathrm{b}, *}$, George Chatzipirpiridis $^{\mathrm{a}}$, \\ Lukas H.J. Martin ${ }^{\mathrm{c}}$, Jordi Sort ${ }^{\mathrm{d}}$, Carlos M. Müller ${ }^{\mathrm{e}}$, Eva Pellicer ${ }^{\mathrm{b}}$, Bradley J. Nelson ${ }^{\mathrm{a}}$, \\ Salvador Pané ${ }^{\mathrm{a}}$ \\ ${ }^{a}$ Multi-Scale Robotics Lab (MSRL), Institute of Robotics E Intelligent Systems (IRIS), ETH Zürich, Zürich 8092, Switzerland \\ ${ }^{\mathrm{b}}$ Departament de Física, Facultat de Ciències, Universitat Autònoma de Barcelona, Campus UAB, Bellaterra 08193, Spain \\ ${ }^{\mathrm{c}}$ Institute of Geochemistry and Petrology, ETH Zürich, Zürich 8092, Switzerland \\ d Institució Catalana de Recerca i Estudis Avançats (ICREA) and Departament de Física, Universitat Autònoma de Barcelona, Campus UAB, Bellaterra, 08193, \\ Spain \\ e Departament de Química Física, Universitat de Barcelona, Barcelona 08028, Spain
}

\section{A R T I C L E I N F O}

\section{Article history:}

Received 23 February 2016

Received in revised form 11 April 2016

Accepted 14 April 2016

Available online 22 April 2016

\section{Keywords:}

NiMnGa

single step electrodeposition

aqueous electrolyte

thin films

\begin{abstract}
A B S T R A C T
An electrochemical synthesis route for NiMnGa alloys is presented. Thin films of NiMnGa were fabricated by single step electrodeposition from aqueous electrolytes using direct current over a range of current densities. By electrolyte tuning, homogeneous films with high Ga and Mn content could be achieved at current densities as high as $-400 \mathrm{~mA} \mathrm{~cm}^{-2}$. Detailed compositional analysis of the alloys showed that growth was homogeneous and oxygen content was minimized. Films plated at very low current densities were found to be nanocrystalline/amorphous. In order to obtain fully crystalline samples, thermal annealing was carried out. Mechanical characterization was assessed by nanoindentation, and the effect of Ga content on mechanical properties was investigated.
\end{abstract}

(C) 2016 Elsevier Ltd. All rights reserved.

\section{Introduction}

Further development in micro- and nanosystems requires the integration of high aspect ratio, miniaturized components made of stoichiometrically relevant multi-alloys $[1,2]$. Despite extensive research on the integration of small architectures made of complex alloys, fabrication processes compatible with small systems manufacturing have not been fully established. Such is the case with Nd-based permanent magnets [3], giant magnetostrictive Terfenol-D [4], and ferromagnetic shape memory alloys, such as NiMnGa [5]. Bulk fabrication techniques are often employed, which may involve melt spinning, crushing and milling, sintering, ingot synthesis, and processing at high temperatures $[3,4,6]$. Bottom-up methods based on physical vapor deposition techniques have also been employed for multi-alloy fabrication due to their compatibility with micro- and nanosystems processing $[1,7,8]$. However, these methodologies are complex and highly limited in aspect ratio [9]. Alternatively, polymer based micro- and

\footnotetext{
* Corresponding authors.

E-mail addresses: oezkaleb@student.ethz.ch (B. Özkale), jordina.fornell@uab.cat (J. Fornell).
}

nanocomposite patterning approaches can be implemented due to their suitability with small-systems fabrication processes. However, the achievable maximum particle content within a composite is often limited due to the inherent requirements of the photolithography process. This in turn can cause significant reduction in device performance [10]. Electrochemical processing methods, such as electrodeposition, offer several advantages over the methods mentioned above. Apart from being compatible with micro- and nanosystems manufacturing technologies, electrodeposition can be employed for the large-scale fabrication of several materials with a wide range of aspect ratios and geometries [9,11]. By adjusting the electrolyte formulation, the temperature, and the operating electrochemical parameters (continuous/pulsating current or potential), the composition, the morphology and the physical properties of deposits can be highly tuned [12,13]. Other advantages include ease of operation and equipment simplicity $[9,11]$.

Multi-alloy systems have been successfully fabricated by means of electrodeposition. Some examples include CoNiFe [14] and CoNiMo [15] for soft magnetic components, ZnNiCo [16,17] as alternative sacrificial coatings, and CuInGa $[18,19]$ for solar cells. While the electrodeposition of three or more metals is feasible, matching the required atomic relationship between the elements 
in the electrodeposit is challenging. This can be due to several reasons such as the deposition mechanism or the synergistic effects occurring when several chemical species (electroactive metal ions and additives) interact. For example, at ordinary electrochemical operating conditions, certain metals such as Mo and $\mathrm{W}$ cannot be usually electrodeposited unless there is another metal present in the bath which induces the deposition of the other element [20].

The NiMnGa system is particularly attractive as it exhibits ferromagnetic shape memory effect. Ferromagnetic shape memory alloys (FSMAs) have emerged as a distinguished subclass of shape memory alloys as they generate large magnetic-field-inducedstrains (MFIS). NiMnGa alloys, the most explored FSMA system, has been reported to show MFIS up to 10\% [21-24] and has been utilized for building actuators for a variety of applications including small-scale propulsion [25] and energy harvesting [26]. Despite extensive studies on alloy stoichiometry [27-31], structure [24,32-35], exhibited MFIS [21,24,34,36], and associated phase transformations [37-40] there are few reports on fabrication methodologies compatible with micro- and nanosystems manufacturing. In this study, we report for the first time on the electrodeposition of NiMnGa alloys from aqueous solutions. So far, NiMnGa thin films have been fabricated using PVD techniques such as magnetron sputtering [7,8,41], plasma assisted sputtering [42], pulsed laser deposition [43], laser beam ablation [44]. Only one report discusses the electrodeposition of layers of $\mathrm{Ni}, \mathrm{Mn}$ and $\mathrm{Ga}$ from three different aqueous electrolytes [5]. To form the alloy, the layers are subsequently thermally annealed. The lack of studies regarding the electrosynthesis of NiMnGa alloys is due to the wide window of standard reduction potentials existing among the three metals. Mn has the most negative standard reduction potential $(-1.18 \mathrm{~V})$ with respect to $\mathrm{Ni}(-0.25 \mathrm{~V})$ and $\mathrm{Ga}(-0.56 \mathrm{~V})$. Moreover, it is very challenging to electrodeposit $\mathrm{Mn}$ in metallic form $[45,46]$. Additionally, solutions of their corresponding metal ions require slightly different $\mathrm{pH}$ conditions in order to form stable electrolytes, thus narrowing the operational $\mathrm{pH}$ window $[13,18,46,47]$.

\section{Experimental}

\subsection{Electrochemical synthesis}

NiMnGa thin films were electrochemically grown on gold substrates using a standard three-electrode cell. A gold coated silicon substrate with an area $0.25 \mathrm{~cm}^{2}$ served as the working electrode. For this purpose, silicon wafers (4-inch) were e-beam evaporated with $25 \mathrm{~nm}$ of titanium and $125 \mathrm{~nm}$ of gold after which they were diced into $1 \times 0.5 \mathrm{~cm}^{2}$ chips. Prior to this, the backside of silicon wafers was sputtered with $1.5 \mu \mathrm{m}$ thick layer of $\mathrm{SiO}_{2}$ in order to assure passivation. The counter electrode was a platinized titanium sheet and $\mathrm{Ag} / \mathrm{AgCl}(3 \mathrm{M} \mathrm{KCl})$ was selected as the reference electrode. All electrochemical experiments were conducted at room temperature using an Autolab PGSTAT302 N potentiostat. During electrodeposition, the bath $(50 \mathrm{ml})$ was constantly stirred at a speed of $500 \mathrm{rpm}$ and a nitrogen blanket over the electrolyte surface was provided. All chemicals except gallium sulfate (Alfa Aesar) were acquired from Sigma Aldrich with analytical purity and used as received. Each experiment was conducted with a freshly prepared bath.

\subsection{Characterization methods}

The morphology of the NiMnGa films was investigated by scanning electron microscopy (SEM, Zeiss ULTRA 55) and also by a focused ion beam (FIB) coupled SEM (Zeiss, NVision 40) for crosssectional viewing. Energy dispersive X-ray (EDX, Zeiss, NVision 40) analysis was used to measure the composition of the films using an acceleration voltage of $15 \mathrm{kV}$ during 50 livetime seconds. Quantification was done using the EDAX Genesis software for the $\mathrm{K}$ lines of the three metals and of oxygen. The distribution of elements within the deposit was studied by EDX element mapping (Zeiss, NVision 40) both on the surface and the cross-section operating at $15 \mathrm{kV}$. Electron probe microanalysis (EPMA, Jeol JXA8200) was performed on a carbon coated TF sample using wavelength dispersive spectrometry (WDS). Operation conditions were $10 \mathrm{kV}$ for the acceleration voltage, $30 \mathrm{nA}$ probe current, using a defocussed beam of $20 \mu \mathrm{m}$ diameter and measuring $20 \mathrm{sec}$ on peak and backgrounds. For $\mathrm{Mn}$, the $\mathrm{K} \alpha$ line was analyzed and for $\mathrm{Ni}$ and $\mathrm{Ga}$, the $\mathrm{L} \alpha$ lines. The standards used are elemental $\mathrm{Mn}$ and $\mathrm{Ni}_{8} \mathrm{Cr}_{2}$ and $\mathrm{V}_{2} \mathrm{Ga}_{5}$ alloys. Results were processed using the PRZArmstrong method as well as the thinfilm method implemented in the EPMA software.

Nanoindentation of as-deposited samples was carried out in a UMIS nanoindenter using a Berkovich pyramidal-shaped tip applying a maximum load of $10 \mathrm{mN}$. A holding period of $20 \mathrm{~s}$ was introduced in all cases before unloading and the thermal drift was always kept below $\pm 0.05 \mathrm{~nm} / \mathrm{s}$. At least 50 indentations were performed on the cross section of the NiMnGa thin films to minimize the errors associated with the roughness of the surface. Prior to indentation, the cross section was carefully polished to mirror-like appearance using diamond paste.

Structural properties were investigated by X-ray diffraction (XRD, Philips X'Pert Pro, $\mathrm{Cu} \mathrm{K} \alpha$ ) analysis using a step size of $0.026^{\circ}$ and step time of 1 seconds for both as-deposited and annealed NiMnGa films. In addition, structural investigation was conducted in a conventional transmission electron microscopy (TEM, JEOL JEM, $200 \mathrm{kV}$ acceleration voltage). Thermal annealing was carried out in a high vacuum Carbolite furnace under vacuum at $250^{\circ} \mathrm{C}$ for 10 hours. Compositional analysis on annealed samples were performed by EDX element mapping of the $\mathrm{K}$ lines in STEM (Talos, FEI, $200 \mathrm{kV}$ ). For this purpose, the samples were prepared by a standard procedure using mechanical polishing, dimpling, and ion milling in Ar atmosphere.

\section{Results and Discussion}

\subsection{Electrochemical Synthesis of NiMnGa alloys}

The aim of this study was to build an electrochemical fabrication platform route for synthesizing NiMnGa thin films with relevant stoichiometries. A single electrolyte containing the three metal salts and several additives was developed. NiMnGa films were electroplated at a wide current density range $(-50 \mathrm{~mA}$ $\mathrm{cm}^{-2}$ to $-400 \mathrm{~mA} \mathrm{~cm}^{-2}$ ). The influence of current density on alloy composition as well oxygen content was studied by EDX and confirmed with EPMA analysis. Surprisingly, oxygen content was minimized while $\mathrm{Mn}$ and Ga deposition was promoted at high current densities. NiMnGa films were further characterized for morphological and compositional homogeneity using scanning SEM and EDX element mapping. The structure of the films was studied for both as-deposited and thermally annealed samples by

Table 1

NiMnGa electrolyte compositions.

\begin{tabular}{ll}
\hline Component & Concentration $(\mathrm{mM})$ \\
\hline Nickel sulfate hexahydrate $\left(\mathrm{NiSO}_{4} \cdot 6 \mathrm{H}_{2} \mathrm{O}\right)$ & 375 \\
Manganese sulfate monohydrate $\left(\mathrm{MnSO}_{4} \cdot \mathrm{H}_{2} \mathrm{O}\right)$ & 200 \\
Gallium sulfate octadecahydrate $\left(\mathrm{Ga}_{2}\left(\mathrm{SO}_{4}\right)_{3} \cdot 18 \mathrm{H}_{2} \mathrm{O}\right)$ & 55 \\
Boric acid $\left(\mathrm{H}_{3} \mathrm{BO}_{3}\right)$ & 315 \\
Trisodium citrate $\left(\mathrm{Na}_{3} \mathrm{C}_{6} \mathrm{H}_{5} \mathrm{O}_{7}\right)$ & 400 \\
Sodium dodecyl sulfate $\left(\mathrm{NaC}_{12} \mathrm{H}_{25} \mathrm{SO}_{4}\right)$ & 0.34 \\
Saccharin sodium salt $\left(\mathrm{C}_{7} \mathrm{H}_{4} \mathrm{NNaO}_{3} \mathrm{~S}\right)$ & 20 \\
\hline
\end{tabular}


XRD and TEM. Mechanical properties were determined through nanoindentation measurements.

The optimized electrolyte utilized throughout all electrochemical experiments is presented in Table 1 . The NiMnGa system was studied in acidic sulfate solutions. Boric acid acted as a pH-buffer, while sodium citrate was used as complexing agent, which is also commonly reported to promote Ga electrodeposition [18,48]. Sodium dodecyl sulfate(SDS) was chosen as surfactant and saccharin acted as a stress reliever. The corresponding speciation diagrams at room temperature were obtained using the Medusa/Hydra software, and are given in the supporting information (Fig. S1). At an operating $\mathrm{pH}$ of 3.3, the speciation diagram in Fig. S1 (a) shows that $\mathrm{Ni}(\mathrm{II})$ species are distributed as aquocomplexes, sulfate ionic pairs and several citrate complexes. The Mn(II) species are mainly (80\%) distributed as $\mathrm{Mn}^{2+}$ aquocomplexes and $\mathrm{Mn}^{2+}$ sulfate ionic pairs, while the rest is in the form of citrates. Concerning $\mathrm{Ga}$ (III) species, the diagram predicts the onset of $\mathrm{Ga}_{2} \mathrm{O}_{3}$ precipitation at a $\mathrm{pH}$ of approximately 2.3. Our system did not show any precipitation of $\mathrm{Ga}$ (III) oxides even at a $\mathrm{pH}$ value of 3.3 when citrate is present in the electrolyte. We conjecture that the stability of the electrolyte is due to the formation of heteronuclear citrate and biscitrate complexes containing both nickel and gallium, which are not predicted by the speciation diagrams. In fact, sodium citrate has been reported to form such heteronuclear complexes containing both $\mathrm{Ni}$ and $\mathrm{Cu}$ [49]. The combination of $\mathrm{Ga}$ (III) hydroxocomplexes with citrate species might be also occurring.

\subsection{Composition, Morphology and Structure Characterization}

The E-t curves for NiMnGa films deposited at three different current densities are shown in Fig. 1. As expected, the overpotential becomes more negative as the absolute value of current density is increased. The corresponding EDX measurement are presented in Fig. 2(a). As expected, at low current densities (i.e. $-50 \mathrm{~mA} \mathrm{~cm}^{-2}$ ), the deposit consists of almost pure Ni due to its more positive reduction potential. On the other hand, a drastic change is observed at -200 and $-400 \mathrm{mAcm}^{-2}$. The amount of $\mathrm{Ga}$ in the deposits was comparable (around 60 at. \%), while a slight decrease from 24 to 22 at. \% for $\mathrm{Ni}$ and an increase from 10 to 15 at. \% for Mn was observed. Surprisingly, at intermediate current densities such as $-100 \mathrm{~mA} \mathrm{~cm}^{-2}$, deposition was highly inhibited due to dominating hydrogen evolution reaction and enhanced galvanic corrosion [50], and therefore these current densities were not further investigated. The chosen electrolyte provided NiMnGa films with low amounts of oxygen at high current densities. One must point out that the determination of the $\mathrm{O}$ content by EDX measurements is not completely accurate, but the decrease in $\mathrm{O}$ was obvious when compared to samples obtained from previous other formulations (see supporting information, Fig. S2). The O

Time / s

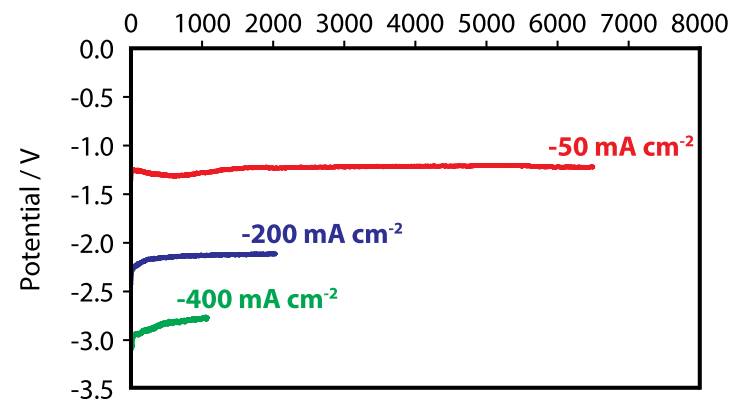

Fig. 1. E-t curves corresponding to the electrodeposition of the NiMnGa films at the indicated current densities. content at very high current densities could be maintained approximately below 10 at. \% under the studied conditions. The highest amount of $\mathrm{O}$ was determined for $-200 \mathrm{~mA} \mathrm{~cm}^{-2}$ (10 at. \%) whereas at a more negative current density it was further reduced (below 5 at. \%). One would expect high $\mathrm{O}$ contents in the deposit at these conditions due to the formation of metal hydroxides. However, other systems such as SnMn studied by Zangari and co-workers exhibit a similar trend. The authors suggest that the electrodeposition rate overcomes the rate of galvanic corrosion of manganese [50]. As the local $\mathrm{pH}$ near the cathode vicinity would also be high, precipitation of $\mathrm{Ga}(\mathrm{III})$ oxohydroxides would be expected. The Ga-rich composition and low $\mathrm{O}$ content in the obtained NiMnGa films suggest that the formation of $\mathrm{Ga}$ (III) precipitates is not favored in our system. Probably, the high $\mathrm{pH}$ generated around the cathode also favors the formation of other complexes, or a redistribution of metal ions among several species of citrate.

In order to verify the alloy stoichiometry, EPMA analysis was conducted for a film fabricated at $-400 \mathrm{mAcm}^{-2}$ as this condition provides alloys with the highest amount of $\mathrm{Mn}$ and Ga. The measurements were done on an unpolished, as-deposited sample and the alloy composition was determined as 31 at. \% Ni, 20 at. \% $\mathrm{Mn}$, and 48 at. \% Ga. Differences between the SEM-EDX and EPMA results were expected as the latter method is standard based compared to the qualitative EDX measurements, still, the Ga-rich nature of our alloys was verified. This composition range is highly attractive since $\mathrm{Ga}_{2} \mathrm{NiMn}$ has been proposed as an alternative to the popular $\mathrm{Ni}_{2} \mathrm{MnGa}$ Heusler alloy due to improved mechanical properties of the former [28]. Indeed, very recently, compositions including $\mathrm{Ga}_{2} \mathrm{NiMn}$ and non-stoichiometric NiMnGa are being prepared by physical means and their properties are being investigated experimentally and theoretically [28,51,52]. Electrodeposited NiMnGa films also exhibited excellent compositional homogeneity across the cross-section as indicated by EDX element mappings for films plated at $-400 \mathrm{mAcm}^{-2}$ (Fig. 2(b)-(e)). The distribution of $\mathrm{Ni}, \mathrm{Mn}$, and $\mathrm{Ga}$ was found to be very uniform over the entire cross-section. The samples obtained at other current density conditions also exhibited comparable compositional homogeneity (see supporting information, Fig. S3). The O K-line map is not included because no significant signal was obtained, thus confirming that the $\mathrm{O}$ content in the deposits is very low.

The morphology of NiMnGa films obtained at three selected current densities was further analyzed. In order to understand the effect of current density on the alloy deposition with regard to their homogeneity, the morphology was investigated both at the surface and in the cross-section. Selected SEM images of as-deposited NiMnGa films are given in Fig. 3. In all three cases, deposits exhibit uniform coverage over the deposition area. At $-50 \mathrm{~mA} \mathrm{~cm}^{-2}$, the Ni-rich films exhibit a shiny gray color and a smooth morphology (Fig. 3 (a)). As expected, at higher current densities, the surface morphology is less smooth and porosity can be observed. Interestingly, while films plated at $-200 \mathrm{~mA} \mathrm{~cm}^{-2}$ (Fig. 3 (b)) are black and exhibit a highly porous surface, deposits obtained at $-400 \mathrm{mAcm}^{-2}$ (Fig. 3 (c)) show a more compact nodular morphology. These samples were slightly shiny with a gray color. Differences in porosity can be distinguished more clearly in the cross-sectional SEM images (Fig. 3(d-f)). Films obtained at $-200 \mathrm{~mA} \mathrm{~cm}^{-2}$ display a distinct dendritic structure, whereas at $-400 \mathrm{~mA} \mathrm{~cm}^{-2}$, a smooth compact deposit can be observed. The higher hydrogen evolution occurring at $-200 \mathrm{~mA} \mathrm{~cm}^{-2}$ can explain this morphology. On the contrary, deposits grown at $-400 \mathrm{~mA}$ $\mathrm{cm}^{-2}$ show both less oxygen content and a more compact morphology. Most probably, the rate of deposition is able to overcome the high hydrogen evolution expected at such high current density. Indeed, a report on Mn deposition explains that deposits obtained at current densities around $-100 \mathrm{mAcm}^{-2}$ are 


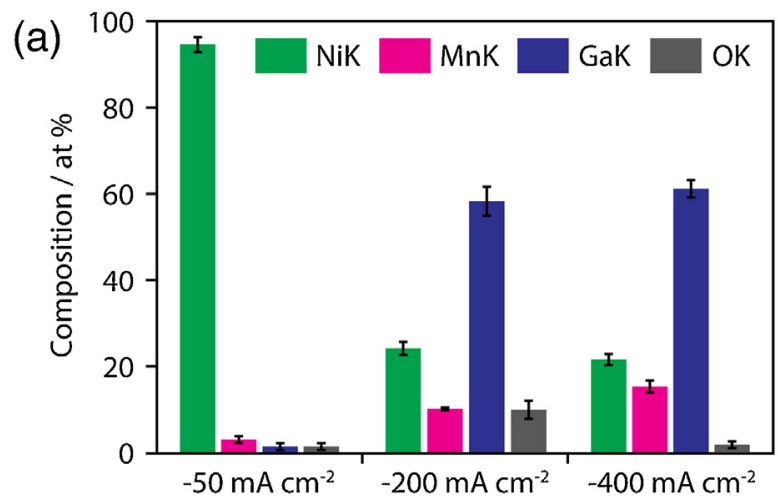

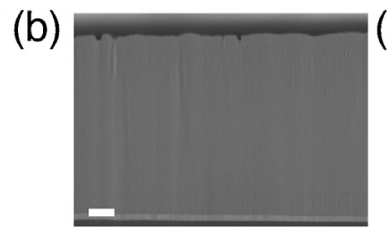
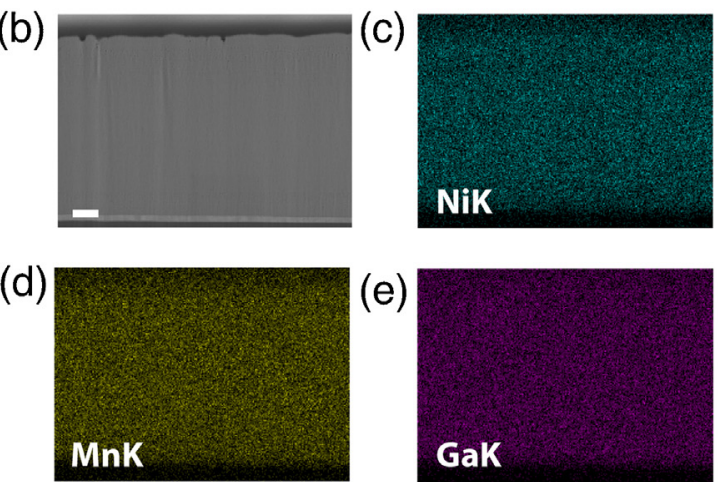

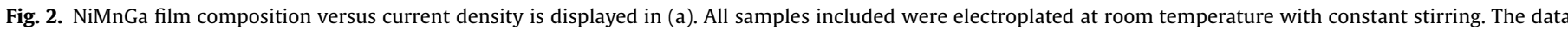

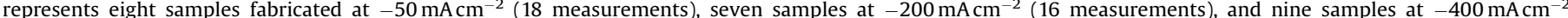

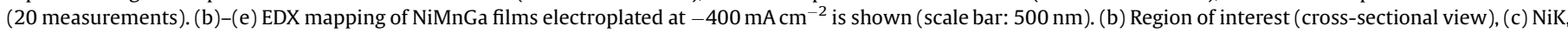
(d) MnK, (e) GaK maps.

(a)

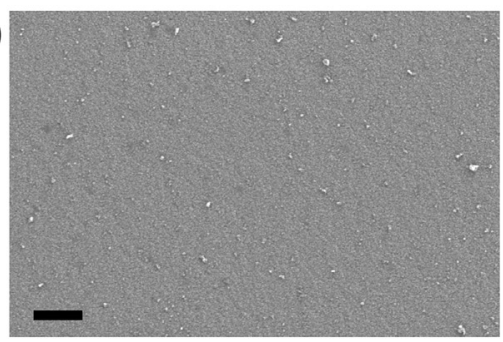

(d)

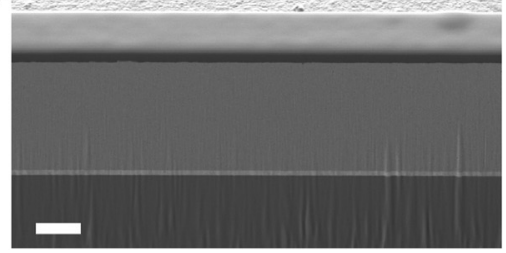

(b)

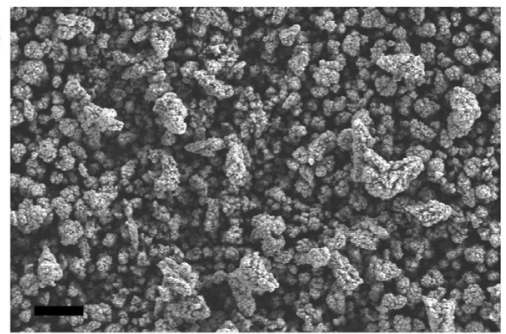

(e)

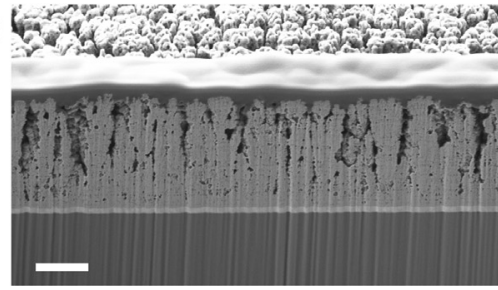

(c)

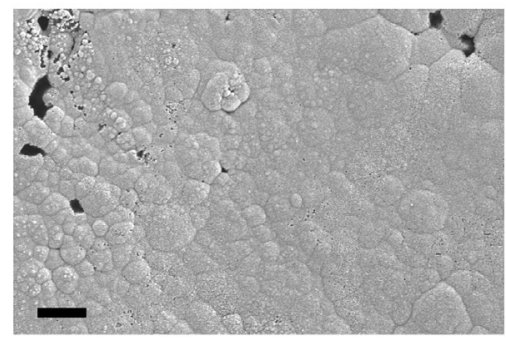

(h)

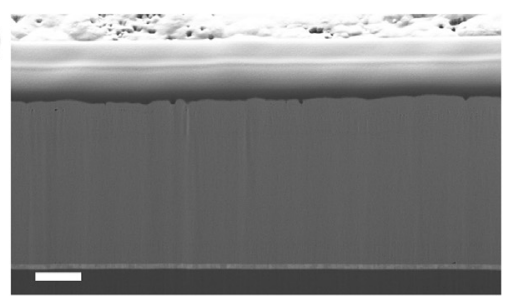

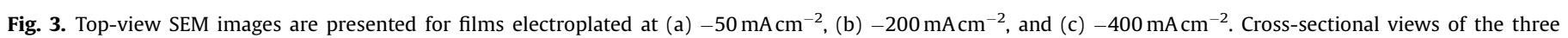
conditions are shown in (d)-(f) respectively. Scale bars show $1 \mu \mathrm{m}$.
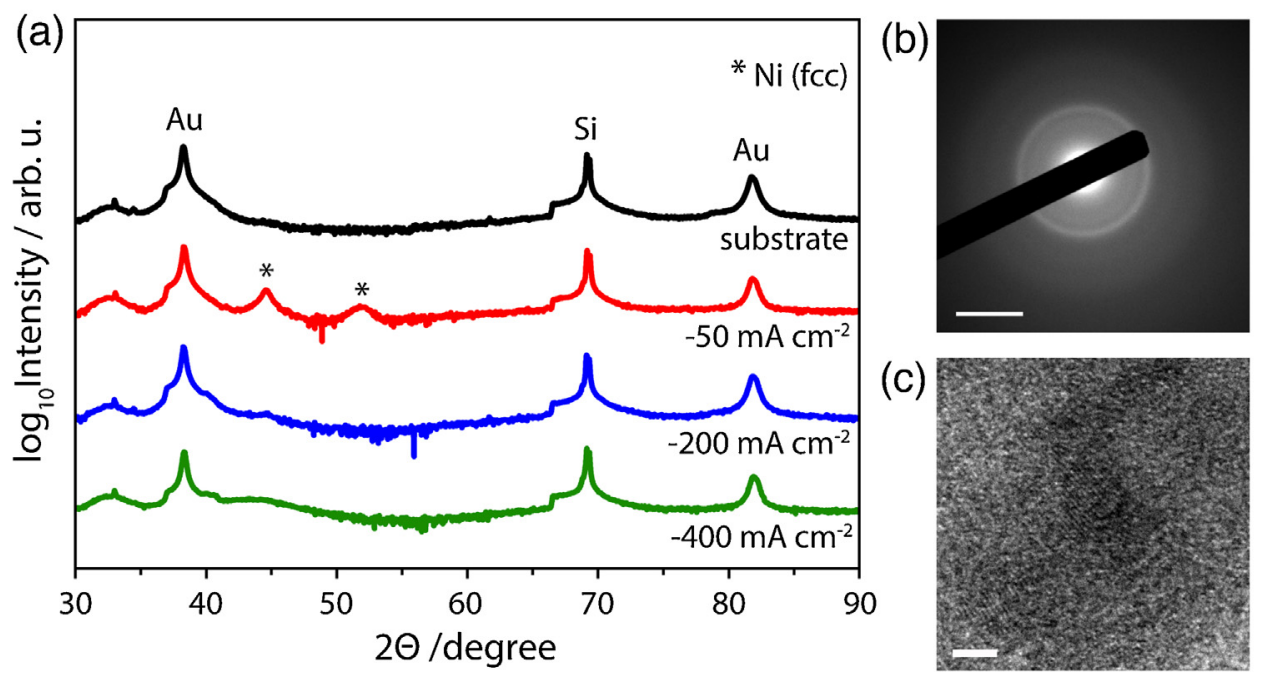

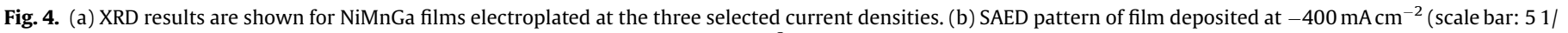
$\mathrm{nm}$ ) is presented. (c) High resolution TEM image of film deposited at $-400 \mathrm{~mA} \mathrm{~cm}^{-2}$ (scale bar: $5 \mathrm{~nm}$ ) is shown. 
not continuous due to deterred nucleation. However, deposits synthesized at current densities above $-150 \mathrm{~mA} \mathrm{~cm}^{-2}$, exhibit a continuous and globular morphology with lowered oxygen content [46,50]. The current efficiencies calculated from the thickness of the deposits were $1.27 \%$ and $1.81 \%$ at -200 and $-400 \mathrm{~mA} \mathrm{~cm}^{-2}$, respectively. The foamy appearance of films obtained at $-200 \mathrm{mAcm}^{-2}$ can be ascribed to temporarily retention of hydrogen bubbles on the deposit by surface tension. The hydrogen evolution reaction is not necessarily negative as the bubbles mix up the electrolyte. Indeed, the formation of pores in fine-grained $\mathrm{Ni}_{2} \mathrm{MnGa}$ can be advantageous as pores decrease the constraints of twin boundary motion through grain boundaries. Müllner [53] and co-workers have shown that porous fine-grained $\mathrm{Ni}_{2} \mathrm{MnGa}$ shows a reversible magnetic-field-induced strain (MFIS) of $0.12 \%$ compared to continuous counterparts, which exhibit nearly a MFIS of $0 \%$. The low current efficiencies are mostly due to the large current densities employed. Nevertheless, other synergistic factors can influence the efficiency of the process as well. While Ni, Ga and Mn can be obtained from different electrolytes with fairly high efficiencies [5,48], the mere presence of their metallic ions in the same electrolyte can drastically drop the current efficiency of the process. For instance, impurities of $\mathrm{Fe}, \mathrm{Co}$, $\mathrm{Ni}$ in manganese electrodeposition can lower the efficiency by about 50\% [45]. Similarly, Ga electrodeposition can be highly inhibited in the presence of metal impurities, which in turn promote the hydrogen evolution reaction [54]. Pulse deposition, the use of ionic liquids, and high pH electrolytes (i.e.: Bayer-process liquors) are strategies to improve current efficiency of NiMnGa deposition.

The structural data presented in Fig. 4 provides more insight on alloy properties. As expected based on the EDX findings, the Ni-rich (96 at. \%) films fabricated at $-50 \mathrm{mAcm}^{-2}$ show reflections matching the face-centered-cubic (fcc) Ni with a cell parameter of $3.5175 \AA$. The peaks located at approximately $44.5^{\circ}$ and $52^{\circ} 2 \theta$ denoted with an asterisk belong to (111) and (200) $\mathrm{Ni}$ fcc reflections respectively. At higher current densities, well-defined peaks could not be distinguished by XRD, however, a broad hump at $44.5^{\circ}$ could indicate the amorphous nature of the films. This loss of crystallinity at high current density regimes has also been described for other systems [55,56]. TEM images showed very small and sparse crystallites for films fabricated at high current densities (Fig. 4(c)). The selected area electron diffraction (SAED) pattern of the films grown at $-400 \mathrm{~mA} \mathrm{~cm}^{-2}$ shows the presence of several diffuse rings, together with very few spots, thus corroborating the nanocrystalline/amorphous structure of this sample, in agreement with the XRD pattern.

In order to promote crystallinity and grain growth, NiMnGa films were annealed at $250^{\circ} \mathrm{C}$ for 10 hours under vacuum. The annealing temperature was kept low in order to minimize interdiffusion of the underlying Au layer into the deposit. Focus was given to films with the highest amount of $\mathrm{Mn}$ and $\mathrm{Ga}$ and the lowest $\mathrm{O}$ content. Therefore, films fabricated at $-400 \mathrm{~mA} \mathrm{~cm}^{-2}$ were utilized in annealing experiments. The resulting samples were characterized with regard to their compositional homogeneity and structure in detail. EDX element mapping in STEM was performed on cross-sections of annealed NiMnGa films and the results are presented in Fig. 5(a)-(d). The results indicate that the compositional homogeneity is preserved during thermal annealing while grain growth is successfully promoted (Fig. 5(e)). Among the reflections observed by XRD, 5 reflections (marked with asterisk in Fig. 5(e)) characteristic of the austenite fcc phase were identified assuming a cell parameter of $5.77 \AA$. This cell parameter is smaller than the one tabulated for fcc $\mathrm{Ni}_{2} \mathrm{MnGa}(5.82 \AA$ ). Such a reduction of the cell parameter could be related to the larger amount of $\mathrm{Ga}$ in this sample (whose composition is close to $\mathrm{Ga}_{2} \mathrm{NiMn}$ ), since the atomic radius of $\mathrm{Ga}(130 \mathrm{pm})$ is smaller than the one for $\mathrm{Ni}$ $(135 \mathrm{pm})$ and $\mathrm{Mn}(140 \mathrm{pm})$, hence resulting in a smaller lattice constant. However, the remaining peaks could not be unambiguously identified.

\subsection{Mechanical Properties of NiMnGa Alloys}

The effect of the high Ga content (approximately 50 at \%) on the mechanical properties of NiMnGa films was studied by nanoindentation. According to literature, increased Ga concentrations can reduce the brittleness of $\mathrm{Ni}_{2} \mathrm{MnGa}$ alloys [28]. For this purpose, indentations were performed on NiMnGa films in the crosssections. In Fig. 6 two representative load versus depth indentation curves for $\mathrm{Ni}$ - and $\mathrm{Ga}$-rich films are presented. The maximum penetration depth was larger for the Ga-rich alloy meaning that it is mechanically softer than the Ni-rich alloy. Additionally, the initial part of the unloading curve is steeper for the Ni-rich alloy indicating a larger Young's modulus. The reduced Young's modulus $\left(E_{r}\right)$, the hardness $(H)$, and the ratios $H / E_{r}$ and $H^{3} / E_{r}{ }^{2}$, related to the wear properties of the material, are presented in Table 2.

The results reveal that the $H / E_{r}$ ratio, which is an indirect assessment of the wear resistance of the thin film, increases in the alloy with Mn and Ga contents. Another parameter related to the
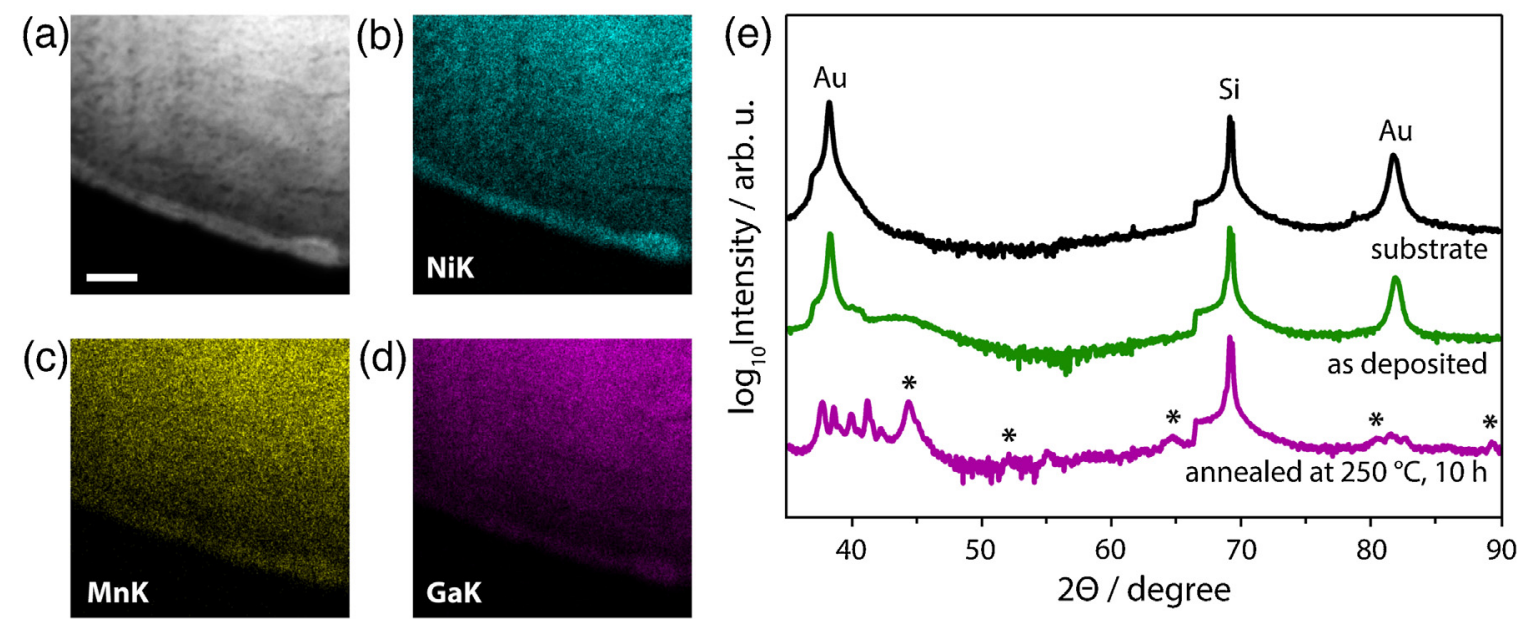

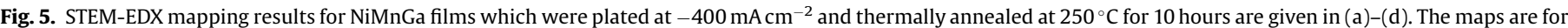

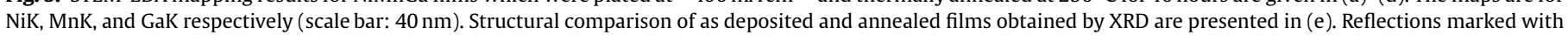
asterisk correspond to the austenite face-centered-cubic (fcc) phase. 

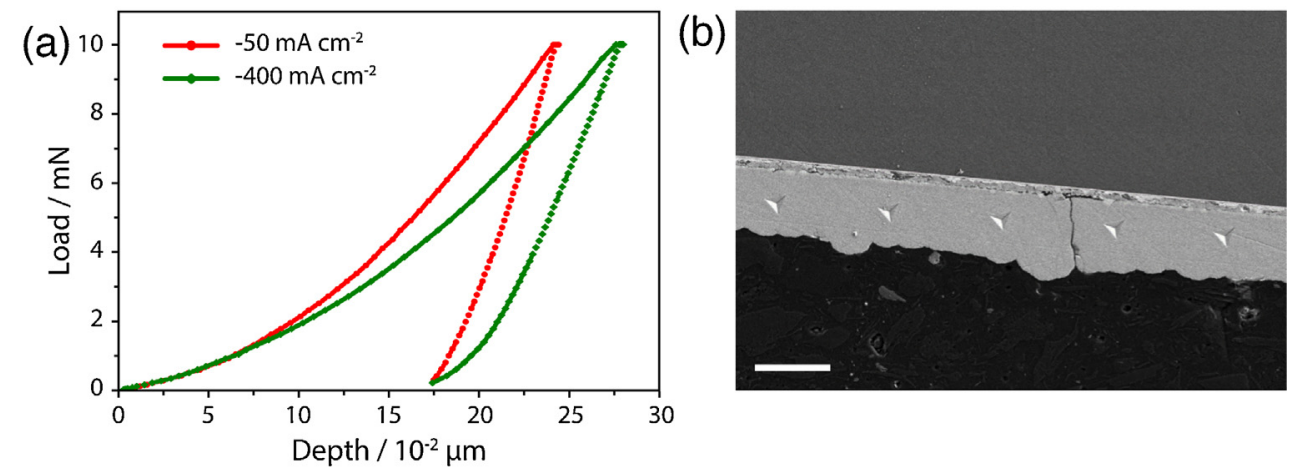

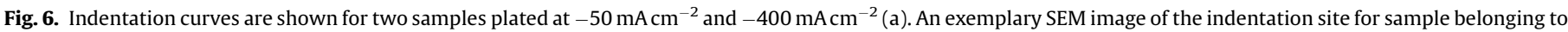
$-400 \mathrm{~mA} \mathrm{~cm}^{-2}$ condition (scale bar: $10 \mu \mathrm{m}$ ) is given in (b).

Table 2

Several important parameters calculated from nanoindentation curves are presented.

\begin{tabular}{lrlll}
\hline$-\mathrm{j}\left(\mathrm{mA} \mathrm{cm}^{-2}\right)$ & \multicolumn{1}{l}{$E_{r}(\mathrm{GPa})$} & $H(\mathrm{GPa})$ & $H / E_{r}$ & $H^{3} / E_{r}{ }^{2}$ \\
\hline 50 & $145.3 \pm 5.3$ & $7.88 \pm 0.45$ & 0.05415 & 0.02307 \\
400 & $96.8 \pm 5.4$ & $7.18 \pm 0.56$ & 0.07415 & 0.03948 \\
\hline
\end{tabular}

wear characteristics is the $H^{3} / E_{r}^{2}$ ratio. This parameter is also indicative of the resistance of the material to plastic deformation under loaded contact, i.e., the so-called yield pressure. Again the $H^{3} / E_{r}^{2}$ ratio indicates that the alloy with $\mathrm{Mn}$ and Ga results in optimized wear performance [57].

\section{Conclusion}

A fabrication approach for NiMnGa alloys is presented and discussed. NiMnGa films with significantly high Mn (20 at. \%) and Ga (49 at. \%) content could be synthesized by single step electrodeposition from aqueous baths. The resulting films were found to be compositionally homogeneous and almost completely free of oxygen despite the applied high current densities. In this regard, electrolyte composition, specifically the choice of complexing agent and other additives, was observed to be the key for the co-deposition. This is the first report studying co-deposition of NiMnGa alloys. A detailed structural analysis was performed and crystallinity was improved with thermal annealing. The effect of Ga on mechanical properties was also investigated. The results showed that Ga-rich alloys (grown at $-400 \mathrm{~mA} \mathrm{~cm}^{-2}$ ) are attractive for applications requiring wear resistance. The described fabrication technique holds great potential for miniaturization of multicomponent alloys and provides a basis for further development.

\section{Acknowledgements}

The authors would like to acknowledge the Scientific Center for Optical and Electron Microscopy (ScopeM) at ETH Zurich for providing technical support on FIB SEM, EDX analysis, and TEM work. J.F., E.P., and J.S. acknowledge 2014-SGR-1015 project from the Generalitat de Catalunya. J.F. acknowledges the European Union for the Marie Curie fellowship (FP7-PEOPLE-2012-IOF). E.P. acknowledges the Spanish MINECO for the 'Ramon y Cajal' contract (RYC-2012-10839). S.P. acknowledges financial support by the European Research Council Starting Grant "Magnetoelectric Chemonanorobotics for Chemical and Biomedical Applications (ELECTROCHEMBOTS)", by the ERC grant agreement no. 336456. The authors would like to acknowledge networking support by the cosT Action MP1407.

\section{Appendix A. Supplementary data}

Supplementary data associated with this article can be found, in the online version, at http://dx.doi.org/10.1016/j. electacta.2016.04.071.

\section{References}

[1] M. Pallapa, J.T.W. Yeow, Smart Mater. Struct. 24 (2015) 025007.

[2] E. Faran, D. Shilo, Exp. Tech. (2015), doi:http://dx.doi.org/10.1111/ext.12153.

[3] D. Brown, B.M. Ma, Z. Chen, J. Magn. Magn. Mater. 248 (2002) 432-440.

[4] J. Gong, E.J. Podlaha, 2000, Electrochem. Solid-State Lett. 3 (2000) 422-425.

[5] U. Gaitzsch, J. Drache, K. McDonald, P. Müllner, P. Lindquist, Thin Solid Films 522 (2012) 171-174

[6] D.C. Dunand, P. Müllner, Adv. Mater. 23 (2011) 216-232.

[7] F. Bernard, P. Delobelle, C. Rousselot, L. Hirsinger, Thin Solid Films 518 (2009) 399-412.

[8] V.A. Chernenko, M. Kohl, V.A. L'vov, V.M. Kniazkyi, M. Ohtsuka, O. Kraft, Mater. Trans. 47 (2006) 619-624.

[9] I.M. Dharmadasa, J. Haigh, J. Electrochem. Soc. 153 (2006) G47.

[10] C. Peters, O., Ergeneman, G. A. Sotiriou, S. E. Pratsinis, B. J. Nelson, C. Hierold, Solid-State Sensors, Actuators and Microsystems (TRANSDUCERS \& EUROSENSORS XXVII), 2013 Transducers \& Eurosensors XXVII: The 17th International Conference on (2013) 2676-2679 10.1109/ Transducers.2013.6627357.

[11] J. Han, E. Khoo, P. Bai, M.Z. Bazant, Sci. Rep. 4 (2014) 7056.

[12] M. Schwartz, N.V. Myung, K. Nobe, J. Electrochem. Soc. 151 (2004) C468-C477.

[13] O. Ergeneman, K.M. Sivaraman, S. Pané, E. Pellicer, A. Teleki, A.M. Hirt, D.M. Baró, B.J. Nelson, Electrochim. Acta 56 (2011) 1399-1408.

[14] Y. Zhuang, E.J. Podlaha, J. Electrochem. Soc. 147 (2000) 2231-2236.

[15] E. Gómez, E. Pellicer, E. Vallés, Electrochem. Commun. 7 (2005) 275-281.

[16] M.M. Abou-Krisha, H.M. Rageh, E.A. Matter, Surf. Coat. Technol. 202 (2008) 3739-3746.

[17] N. Eliaz, K. Venkatakrishna, A. Chitharanjan Hegde, Surf. Coat. Technol. 205 (2010) 1969-1978.

[18] L. Ribeaucourt, G. Savidand, D. Lincot, E. Chassaing, Electrochim. Acta 56 (2011) 6628-6637.

[19] Y. Lai, J. Liu, J. Yang, B. Wang, F. Liu, Z. Zhang, J. Li, Y. Liu, J. Electrochem. Soc. 158 (2011) D704-D709.

[20] N. Eliaz, T.M. Sridhar, E. Gileadi, Electrochim. Acta 50 (2005) 2893-2904.

[21] K. Ullakko, J.K. Huang, C. Kantner, R.C. O'Handley, V.V. Kokorin, Appl. Phys. Lett. 69 (1996) 1966-1968.

[22] S.J. Murray, M.A. Marioni, A.M. Kukla, J. Robinson, R.C. O’Handley, S.M. Allen, J. Appl. Phys. 87 (2000) 5774-5776.

[23] P. Múllner, V.A. Chernenko, M. Wollgarten, G. Kostorz, J. Appl. Phys. 92 (2002) 6708-6713.

[24] M. Chmielus, X.X. Zhang, C. Witherspoon, D.C. Dunand, P. Müllner, Nat. Mater. 8 (2009) 863-866.

[25] O.Y. Kanner, D. Shilo, J. Sheng, R.D. James, Y. Ganor, Smart Mater. Struct. 22 (2013) 085030.

[26] I. Karaman, B. Basaran, H.E. Karaca, A.I. Karsilayan, Y.I. Chumlyakov, Appl. Phys Lett. 90 (2007) 172505.

[27] S. Banik, A. Chakrabarti, U. Kumar, P.K. Mukhopadhyay, A.M. Awasthi, R. Ranjan, J. Schneider, B.L. Ahuja, S.R. Barman, Phys. Rev. B 74 (2006) 085110.

[28] S.R. Barman, A. Chakrabarti, S. Singh, S. Banik, S. Bhardwaj, P.L. Paulose, B.A Chalke, A.K. Panda, A. Mitra, A.M. Awasthi, Phys. Rev. B 78 (2008) 134406.

[29] X. Jin, M. Marioni, D. Bono, S.M. Allen, R.C. O’Handley, T.Y. Hsu, J. Appl. Phys. 91 (2002) 8222-8224.

[30] P. Lázpita, J.M. Barandiarán, J. Gutiérrez, J. Feuchtwanger, V.A. Chernenko, M.L. Richard, New J. Phys. 13 (2011) 033039.

[31] K. Vallal Peruman, M. Mahendran, S. Seenithurai, Phys. B Condens. Matter 405 (2010) 1770-1774. 
[32] A.M. Jakob, M. Hennes, M. Müller, D. Spemann, S.G. Mayr, Adv. Funct. Mater. 23 (2013) 4694-4702.

[33] T. Lograsso, K.M. Krishnan, IEEE Trans. Magn. 37 (2001) 2141-2143.

[34] E. Pagounis, R. Chulist, M.J. Szczerba, M. Laufenberg, Appl. Phys. Lett. 105 (2014) 052405

[35] L. Righi, F. Albertini, E. Villa, A. Paoluzi, G. Calestani, V.A. Chernenko, S. Besseghini, C. Ritter, F. Passaretti, Acta Mater. 56 (2008) 4529-4535.

[36] S.J. Murray, M. Marioni, S.M. Allen, R.C. O’Handley, T.A. Lograsso, Appl. Phys. Lett. 77 (2000) 886.

[37] P.J. Brown, J. Crangle, T. Kanomata, M. Matsumoto, K. Neumann, B. Ouladdiaf, K R.A. Ziebeck, J. Phys. Condens. Matter 14 (2002) 10159-10171.

[38] X.Q. Chen, X. Lu, Z.X. Qin, Mater. Sci. Technol. 25 (2009) 829-832.

[39] K. Tsuchiya, A. Ohashi, D. Ohtoyo, H. Nakayama, M. Umemoto, P.G. McCormick, Mater. Trans. 41 (2000) 938-942.

[40] P.J. Webster, K.R.A. Ziebeck, S.L. Town, M.S. Peak, Philos. Mag. Part B 49 (1984) 295-310.

[41] M. Ohtsuka, M. Matsumoto, K. Itagaki, Mater. Sci. Eng. A 438-440 (2006) 935-939.

[42] G. Girard, S. Béchu, N. Caillault, L. Carbone, L. Ortega, D. Fruchart, J. Alloys Compd. 465 (2008) 35-40.

[43] A. Hakola, O. Heczko, A. Jaakkola, T. Kajava, K. Ullakko, Appl. Surf. Sci. 238 (2004) 155-158.
[44] C.Y. Chung, V.A. Chernenko, V.V. Khovailo, J. Pons, E. Cesari, T. Takagi, Mater. Sci. Eng. A 378 (2004) 443-447.

[45] P. Wei, O.E. Hileman, M.R. Bateni, X. Deng, A. Petric, Surf. Coat. Technol. 201 (2007) 7739-7745

[46] J. Gong, G. Zangari, J. Electrochem. Soc. 151 (2004) C297-C306.

[47] P.D. McGary, K.S.M. Reddy, G.D. Haugstad, B.J.H. Stadler, J. Electrochem. Soc. 157 (2010) D656-D665.

[48] J. Gong, G. Zangari, J. Electrochem. Soc. 149 (2002) C209-C217.

[49] T.A. Green, A.E. Russell, S. Roy, J. Electrochem. Soc. 145 (1998) 875-881.

[50] J. Gong, G. Zangari, Mater. Sci. Eng. A 344 (2003) 268-278.

[51] P. Lázpita, J. Gutierrez, J.M. Barandiarán, V. Chernenko, C. Mondelli, L. Chapon, J. Phys.: Conf. Ser. 549 (2014) 012016.

[52] M.V. McLeod, A.K. Giri, B.A. Paterson, C.L. Dennis, L. Zhou, S.C. Vogel, O. Gourdon, H.M. Reiche, K.C. Cho, Y.H. Sohn, R.D. Shull, B.S. Majumdar, Acta Mater. 97 (2015) 245-256.

[53] M. Chmielus, X.X. Zhang, C. Witherspoon, D.C. Dunand, P. Müllner, Nature Mater 8 (2009) 863-866.

[54] R. Dorin, E.J. Frazer, J. Appl. Electrochem. 18 (1988) 134-141.

[55] J. Gong, I. Zana, G. Zangari, J. Mater. Sci. Lett. 20 (2001) 1921-1923.

[56] M.A. Farzaneh, K. Raeissi, M.A. Golozar, J. Alloys Compd. 489 (2010) 488-492.

[57] A. Leyland, A. Matthews, Wear 246 (2000) 1-11. 